Masculinidades y feminidades en la música metal

Manuela Belén Calvo

Con X (N. ${ }^{\circ}$ ), e035, 2020

ISSN 2469-0333 | https://doi.org/10.24215/24690333e035

http://perio.unlp.edu.ar/ojs/index.php/conequis

FPyCS | Universidad Nacional de La Plata

La Plata | Buenos Aires | Argentina

\title{
Masculinidades y feminidades en la música metal
}

\section{Masculinities and Femininities in Metal Music}

\author{
Manuela Belén Calvo \\ manuela.calvo@econ.unicen.edu.ar \\ http://orcid.org/0000-0002-5704-3656 \\ Consejo Nacional de Investigaciones Científicas y Técnicas (CONICET) \\ Instituto de Geografía, Historia y Ciencias Sociales \\ Universidad Nacional del Centro de la Provincia de Buenos Aires (UNICEN) \\ Argentina
}

\section{Resumen}

En el artículo se desarrolla parte de los resultados de investigación acerca de la escena bonaerense de la música metal entre los años 2013 y 2017. El eje está puesto en la perspectiva de género y en las sexualidades. La escena construye una identidad social predominante a través del paradigma de la autenticidad metálica, que se caracteriza por evaluar la veracidad de les músiques, les aficionades y sus prácticas por medio de parámetros patriarcales. De este modo, les agentes construyen identidades masculinas $\mathrm{y}$ femeninas alternativas que dialogan y tensionan con la heteronormatividad.

Palabras clave | música metal, autenticidad, masculinidad, feminidad

\section{Abstract}

This article develops a part of research results about bonaerense metal music scene since 2013 to 2017. This work focus on issue of gender and sexuality perspectives. This scene has a prevalent social identity that it is constructed through metal authenticity's paradigm. It evaluates the truthfulness of musicians, fans and its practices with patriarchal parameters. Thus, scenic agents produce its alternative male and female identities with dialogues and tensions faced with heteronormativity.

Keywords | metal music, authenticity, masculinity, femininity 


\title{
Masculinidades y feminidades en la música metal
}

\author{
Por Manuela Belén Calvo
}

El metal es un género musical que nació a partir de la fusión del blues y el rock psicodélico. A pesar de que no existe una historia definitiva (Janotti Jr., 2004), gran parte de les autores coincide en que sus principales características se cristalizaron a fines de la década del setenta con la Nueva Ola del Heavy Metal Británico (Weinstein, [1991] 2000). Posteriormente, se popularizó en los ochenta, junto con su expansión por el mundo globalizado. Surgieron, así, escenas metálicas en gran cantidad de países, en los cuales tanto la música como su cultura adquirieron características particulares vinculadas con los diversos contextos.

En el presente artículo se desarrolla parte de los resultados de investigación de la tesis doctoral en Comunicación acerca de la escena metálica bonaerense entre los años 2013 y $2017 .{ }^{1}$ El objetivo de dicho estudio fue comprender los modos en que su gran diversidad de agentes y de significados se mantiene cohesionada. En el estudio se concluyó que esto se produce a través del diálogo y de la puja con una forma de identidad social predominante que define la autenticidad metálica por medio de diversos tópicos. Uno de ellos, sobre el cual se elabora este trabajo, vinculado con la sexualidad y con las perspectivas de género. ${ }^{2}$

En las escenas y en las comunidades metálicas a lo largo del mundo, los debates y las reflexiones acerca de la autenticidad están muy presentes, debido a que dichas culturas se caracterizan por la necesidad de discutir y de definir, constantemente, 
las fronteras que indican lo que integra y lo que queda excluido del metal (Weinstein, [1991] 2000; Janotti Jr., 2004; Wallach \& Levine, 2013). A nivel global, esta autenticidad se caracteriza, entre otros aspectos, por el predominio de códigos vinculados con la masculinidad heteronormativa.

Para abordar este tópico, se tomaron como base algunos estudios que han caracterizado la autenticidad musical en diversos géneros musicales por su dimensión masculina (Fischerman, 2004; Arenillas Meléndez, 2016). En efecto, como deudor de la tradición del rock, el metal busca oponerse a la supuesta feminidad del pop y de la música mainstream (Frith \& McRobbie, 1978).

En la Argentina, diversos trabajos dieron cuenta de la masculinidad que predomina en la cultura del rock (Alabarces, 1995; Manzano, 2011) y del metal (Vila, 1985; Flores, 1993; Minore, 2016; Adamo \& Tellis, 2017; Adamo, 2018). Sin embargo, no se han problematizado los modos en que dicha perspectiva de género opera por medio de parámetros éticos y morales de autenticidad, noción que es utilizada para otorgar legitimidad a determinados géneros, estilos y expresiones musicales, no solo por sus elementos sonoros sino también culturales, los cuales permiten identificar lo que es bueno y aceptable.

Por medio de esta autenticidad es que se define al verdadero metal, que se caracteriza por posicionarse ideológicamente en contra de la cultura de masas y de los productos culturales de entretenimiento (especialmente, los vinculados a la moda, el baile y lo femenino); por denunciar y por otorgarle valor a las experiencias de los varones de clase obrera que sufren las desigualdades del sistema capitalista y la discriminación por parte de la cultura hegemónica; además de celebrar a la amistad homosocial y a la familia como relaciones sociales genuinas. En consecuencia, es sobre este supuesto que surgen preguntas acerca de los modos en que las mujeres y las personas con identidades genéricas y sexuales no normativas interactúan con dichos códigos de autenticidad metálica y generan diversas formas de identificarse individual y socialmente con la cultura del metal.

A diferencia del trabajo de Amber Clifford-Napoleone (2015), que propone indagar el lugar de lo queer dentro de la cultura del metal a partir de una perspectiva también queer -es decir, que no acepta la distinción de géneros como una característica dada-, en este artículo se asumen las implicaciones y las limitaciones que devienen de mi lugar de investigadora mujer heterosexual que, a su vez, formaba parte de la escena estudiada desde antes de comenzar la pesquisa. Esto tuvo como consecuencia 
la necesidad de realizar un fuerte proceso de reflexividad que permitiera revisar las perspectivas metálicas masculinizadas y heteronormativas naturalizadas de manera inconsciente y que, para un observador externo, eran fácilmente identificables.

Para este trabajo, se consideró la escena como una red social de personas, de sentidos y de instituciones, por lo que la etnografía multisituada fue una de las principales herramientas metodológicas que permitió abordar la agencia de músiques, productores y aficionades, tanto en eventos especializados (recitales y ferias) como en encuentros casuales, online y offline. De esta manera, se utilizó la observación participante, la netnografía (del Fresno, 2011), la autoetnografía y, dentro de ella, la moshografía (Riches, Lashua \& Spraklen, 2014) para la indagación dentro de la práctica del pogo.

A continuación, se describe, primero, cómo se construye la autenticidad mediante el paradigma de la masculinidad heteronormativa y, luego, se analiza de qué manera dichos códigos regulan las prácticas culturales de la escena y generan tensiones en la agencia de las mujeres metálicas y de aficionades provenientes de la comunidad LGBTTTIQ+. La agencia de las primeras es descrita, particularmente, a través de dos prácticas culturales (el atuendo y el pogo) que permiten analizar la construcción de feminidades metálicas como feminidades alternativas.

\section{La construcción de la masculinidad metálica}

Diverses autores dan cuenta del modo en que la masculinidad funciona como base de la construcción cultural del metal (Weinstein, [1991] 2000; Walser, [1993] 2014; Martínez García, 2003; Janotti Jr., 2004); primero, porque dicho espacio ha sido mayormente ocupado por participantes varones,,$^{3}$ luego, porque tanto la sonoridad como las performances asociadas al metal personifican rasgos masculinos (Janotti Jr., 2013).

Esto significa que, dado que el género es una construcción cultural performativa (Butler, [1990] 2007), en la producción de diversas identidades metálicas se dialoga con códigos que culturalmente fueron definidos como masculinos. No obstante, es necesario destacar que las masculinidades que se presentan en este proceso poseen dos características: por un lado, se trata de formas alternativas a la considerada hegemónica; por otro, prevalece en ellas el binarismo heteronormativo. 
Respecto de lo primero, es posible decir que, en general, el metal ha sido caracterizado por los modos en que representó y resignificó la idea de poder tanto musical como extramusicalmente (Martínez García, 1997; Weinstein, [1991] 2000; Walser, [1993] 2014). Este rasgo parecería acercarse a la descripción que se hace de la masculinidad hegemónica, la cual «[...] es un hombre en el poder, un hombre con poder y un hombre de poder» (Kimmel, 1997, p. 51. Destacado original). De hecho, la potencia sonora del metal también ha sido calificada como agresiva, lo que permitiría equipararla con la violencia simbólica que caracteriza a la dominación masculina (Bourdieu, 2000).

Sin embargo, el metal y sus aficionades se han identificado, principalmente, con figuras marginales -el «paria orgulloso» (Weinstein, 2000)-. Por lo tanto, en lugar de despliegue de poder, se podría hablar de empoderamiento (Rappaport, 1984), ya que les aficionades al metal utilizan a la música como una herramienta para ganar control sobre sus vidas, enfrentar las adversidades y sobrellevar las condiciones de opresión y de marginalidad.

Entonces, tal como sucede en la tradición del rock (Manzano, 2011), en la escena bonaerense el metal dialoga con formas masculinas que se oponen a la figura hegemónica del varón oficinista, prolijo, de buena educación y posición económica favorable. Para ello, se resignifican elementos culturales de figuras varoniles alternativas y contrahegemónicas, las cuales se presentan tanto en la estética de las producciones musicales y de los cuerpos de les agentes, como en la gestualidad y en las formas de comunicación interpersonal.

Por ejemplo, se dialoga con personificaciones de varones pertenecientes a formaciones sociales que históricamente fueron consideradas bárbaras: los pueblos originarios y ancestrales, como los nativos sudamericanos y nórdicos. De esta manera, muches aficionades comparan el uso del cabello largo y desarreglado con las características estéticas de los aborígenes, o llevan largas barbas y peinados tal como los utilizaban los guerreros vikingos.

Visualmente, y dentro de la escena, el aborigen ha sido representado como varón guerrero en varias portadas de discos. En algunos casos, caracterizado con cuerpo atlético (como en el demo de 2013 de la banda de thrash metal Rotas Cadenas) y, en otros, como un ser antropomórfico (tal como sucede en las portadas de los discos Justicia o resistencia y Nuevo Orden Mundial, de Malón). 
El primer caso dialoga con la tradición épica del metal y con la referencia a conflictos bélicos como fuente temática para representar el caos. En efecto, para Rosemary Lucy Hill (2013), esta línea se reforzó a través de la prensa especializada que construyó la virilidad metálica a través de la imagen del guerrero. En la escena bonaerense, no obstante, esta valoración no se produce mediante su representación como militar, sino por medio de la actitud de vida de enfrentar adversidades y a través de sus representantes aborígenes, que socialmente ocupan un lugar de marginalidad.

Con respecto al antropomorfismo, es posible observar que la virilidad es ligada a la imaginería del terror. Tal como sucede en la escena global del metal extremo, en el caso bonaerense también se utiliza la figura del macho cabrío (símbolo de Satanás o de Baphomet, en algunas corrientes ocultistas) tanto en el arte de tapa de discos y en escenografías como en elementos corporales como tatuajes, colgantes y remeras. Al igual que lo bélico, el esoterismo permanece en el metal como fuente temática de transgresión, tal como sucede en las tradiciones del rock y el blues. Esto les permitía oponerse a la moral hegemónica del cristianismo y de la Iglesia Católica.

De la misma corriente, también se revaloriza la figura del motoquero, el cual ha sido caracterizado como agresivo y viril (Willis, 2014). Como figuras extraídas de las culturas locales, se pueden mencionar el compadrito y el gaucho, que se observan, principalmente, en la banda Almafuerte. El primero proviene del tango y se presenta a partir de la descripción de valores ligados a la amistad entre varones, como el coraje y la lealtad. El segundo surge a partir del diálogo con el folklore y con la revalorización de la vida rural y de su habitante prototípico que, desde los discursos dominantes, había sido caracterizado como «inferior, antihigiénico, cruel, bárbaro, perezoso» (Plesch, 2013, p. 340).

Las figuras varoniles mencionadas también se caracterizan por haber sido consideradas peligrosas por parte de sectores hegemónicos. De esta manera, el metal resignifica formas masculinas identificadas como amenazantes y atemorizantes (Weinstein, [1991] 2000; Hill, 2013) para generar rechazo en les agentes externos a la escena metálica. A pesar de que este procedimiento utiliza principalmente referentes masculinos, este modo de identificación también es realizado por aficionades de diversos géneros. 
Otra de las maneras en que la escena metálica bonaerense se opone a lo aristocrático y a la buena educación se produce por medio de gestualidades, de prácticas y de modos del habla culturalmente calificados como groseros y opuestos al recato con el que se suele caracterizar a la feminidad. En las etnografías, varios aficionados varones reforzaban su masculinidad por medio de prácticas como descuidar la higiene propia o del lugar en el que se encontraban (arrojaban vasos al suelo, escupían, eructaban de forma exagerada y orinaban en lugares públicos). Muchos, además, se identificaban con la canción «Sucio y desprolijo» (1972) de Pappo’s Blues.

No obstante, la gestualidad grosera convive con la exaltación del metal como un género musical culto, debido a su tecnicismo y al diálogo que sostiene con la literatura, lo cual es revalorizado en la Feria del Libro Heavy ${ }^{4}$ y en los nuevos círculos intelectuales de la escena. En esta línea, algunos grupos de investigación especializados en metal optan por mezclar el lenguaje formal de la academia y del discurso escrito con expresiones coloquiales propias de la oralidad y el lunfardo. Aunque es probable que este procedimiento busque oponerse a la figura del intelectual burgués, también se lo puede interpretar como una forma de masculinidad contrahegemónica.

En este sentido, en la escena metálica bonaerense se le otorga mayor valor al varón trabajador en tanto obrero, que no solo se opone al oficinista sino también al ladrón, personaje con el cual tanto gran parte de les aficionades al metal como los sectores hegemónicos estigmatizan a les seguidores de cumbia villera. Pese a esto, en la etnografía realizada se dialogó con metaleros que habían estado convictos por delitos tales como robo o comercialización de drogas y con otres que trabajaban en el sector administrativo de empresas y en ocupaciones vinculadas con la programación de sistemas informáticos.

\section{Metal, patriarcado y heteronormatividad}

De acuerdo con Robert Walser ([1993] 2014), el metal se conforma como un discurso que fue moldeado por el patriarcado debido a que ha circulado, principalmente, en sociedades capitalistas occidentales de las que tomó diversos rasgos culturales. En la escena metálica bonaerense, la estructura patriarcal regula los modos de interacción social de sus miembres no solo en el desarrollo de la sexualidad individual, sino también a través de la circulación de normas éticas y morales vinculadas con ideales conservadores como el de la familia tradicional. 
Como se indicó al principio, esta investigación posee algunas limitaciones, ya que se centró, principalmente, en los modos a partir de los cuales la autenticidad metálica opera sobre les agentes de la escena estudiada. Debido a que una de sus principales características es la masculinidad heteronormativa, la pesquisa se centró en los diálogos realizados con dichos códigos y no ahondó en las sexualidades no normativas.

No obstante, en el trabajo de campo realizado se observó el predominio de la heterosexualidad. Esta no solo forma parte de las interacciones públicas que mantienen los miembres de la escena, sino que también aparece en gran cantidad de canciones. La homosexualidad, por su parte, tiene escaso lugar. Solo una mínima parte de les entrevistades admitió una condición sexual no normativa y, por el contrario, la mayoría afirmó no conocer casos de aficionades homosexuales e indicó que, en caso de haberlos, posiblemente no lo expresaran abiertamente por temor a recibir burlas. En este sentido, reconocieron ser un público cerrado, estructurado y «chapado a la antigua», es decir, culturalmente conservador.

Al mismo tiempo, se observó que la grosería -que como se indicó es utilizada en la escena como una estrategia contrahegemónica y de reafirmación de la masculinidadtambién se presenta a través de chistes construidos a partir de la burla hacia un otre que se considera inferior. De manera recurrente, se presentan bromas machistas, discriminatorias y homofóbicas. «Puto» es el adjetivo que, de manera reiterada, se utiliza para insultar a quien no se anima a vestir el atuendo metálico o a participar del pogo, prefiere estilos de metal considerados falsos o blandos (como el glam metal o el emocore) o se preocupa por el aseo personal y la higiene.

Esto se debe a que, siguiendo la tradición del rock, en la escena metálica bonaerense la homosexualidad suele ser ligada a la debilidad y a la feminidad (Kahn-Harris, 2007), lo que es reforzado por el modelo de ciudadanía que configuró el Estado argentino: masculino, blanco, católico, natural y heterosexual, opuesto a lo femenino (que incluyó tanto a las mujeres como a los sexo-disidentes) y con una moralidad que condenaba a quienes llevaban una mala vida (los homosexuales y las prostitutas) (Simonetto, 2016).

$\mathrm{Al}$ momento de realizar la investigación, no obstante, las mujeres lesbianas eran más fácilmente aceptadas que los varones gays, por ser incluidas, con frecuencia, como objeto de heteroerotismo tal como sucede en el videoclip del tema musical «Deseo», de la banda O’Connor. Pese a ello, dentro de la escena, las interacciones sexuales 
y las prácticas de género por fuera de la heteronormatividad parecían estar mal vistas y solían ser ridiculizadas, lo que posibilitaba la invisibilización de aficionades al metal miembres del colectivo LGBTTTIQ+.

Esta característica, sin embargo, se modificó en los años posteriores al cierre del trabajo de campo con el surgimiento de la grupa Unión Transfeminista en el Under (UTFU), que reúne a mujeres, lesbianas, travestis y trans, autoconvocades y autogestionades con el objetivo de visibilizar, de cuestionar y de erradicar dentro de la escena la violencia, y los macro y micro machismos, ya que consideran que como miembres nunca fueron completamente bienvenides.

Tanto en el caso de este colectivo -que utiliza como lema el título de la canción «Some heads are gonna roll» (Algunas cabezas van a rodar)- como en el de aquelles aficionades gays y lesbianas que estuvieron presentes en la etnografía, se observó que utilizaban la figura del cantante Rob Halford, y de su banda Judas Priest, como forma de identificarse, al mismo tiempo, con el metal y con las sexo-disidencias. Esto se debe a que dicho artista es reconocido por ser uno de los primeros músicos metálicos en asumir abiertamente su homosexualidad.

La heteronormatividad también se presenta a través de la revalorización de la familia en su formato tradicional, es decir, conformada por un varón y por una mujer cisgénero, de los cuales el padre desarrolla el rol de sostén económico y la madre queda relegada a la domesticidad y al cuidado de personas. Este ideal es apreciado por la mayor parte de los miembres de la escena, a pesar de que no sea frecuente en la práctica. En contraste, se observaron varios casos de parejas separadas que tienen hijes como fruto de relaciones durante la juventud, familias ensambladas y gran cantidad de aficionades que eligen no tener una pareja sexual estable. A pesar de ello, dentro de la escena, la monogamia es ampliamente valorada.

El valor de la familia se refuerza con la crianza de les hijes, de manera que muches aficionades intentan inculcarles el gusto por el metal, su cultura y sus valores, tanto en varones como en mujeres. Como consecuencia, se constató la presencia de gran cantidad de bebés y de niñes vestides con remeras con logotipos de bandas de metal, especialmente, durante recitales y ferias metálicas. En efecto, algunas familias conformadas por aficionades al metal eligieron para sus hijes nombres relacionados con dicho género musical, especialmente con títulos de canciones y con nombres de músiques y de bandas. 
Paralelamente, en las entrevistas, muches aficionades afirmaron haber conocido el metal a través de familiares como madres y padres, tíes, hermanes, padrinos y madrinas. Esto sucede, más comúnmente, en jóvenes menores de 30 años - es decir, nacidos a partir de la década del noventa-, lo que marca una diferencia con las generaciones anteriores que, de acuerdo con Walser ([1993] 2014), se caracterizaban por utilizar al metal como una forma de rebelión edípica, para diferenciarse del mundo adulto y de la tradición patriarcal.

La estructura familiar también se presenta en la visión de la escena metálica como una hermandad. Este ideal refleja el deseo de construir una comunidad que, a pesar de encontrarse geográficamente dispersa, se mantiene unida mediante la cooperación y el amor por la música (Weinstein, [1991] 2000). A través de la netnografía se relevaron grupos de Facebook con nombres tales como "Hermandad metalera» o «Unión metalera argentina». Esta caracterización, sin embargo, es un ideal en sí mismo que contrasta con las desigualdades presentes en los intercambios offline y que refuerza lo que Hill (2013) denomina «mito de la igualdad».

Como se mencionó, el sistema patriarcal también se presenta en el carácter culturalmente conservador del metal. Por medio de este, les aficionades valoran las formas culturales y las relaciones sociales que trascienden generaciones. En consecuencia, tanto las audiencias como les productores y los medios de comunicación les otorgan prestigio a les músiques de la vieja escuela y a las bandas de culto, a la vez que son reticentes con las nuevas tendencias.

Esto se presenta con mayor énfasis en les miembres más antigües de la escena (de entre 40 y 60 años), quienes prefieren las bandas pioneras del género metálico y consideran que este fue arruinado con el nacimiento de estilos nuevos como el ñu metal. Los subgéneros más contemporáneos son consumidos, principalmente, por aficionades con menos de 30 años, quienes también reconocen a las bandas más antiguas como las genuinas.

Durante el período que comprendió esta investigación, les músiques de las primeras generaciones metálicas transitaban edades adultas. Al contrario que rebeldía, el respeto hacia elles hace que les aficionades de la escena le otorguen a la adultez poder y autoridad. Estos miembres varones son considerados padres de la tradición metálica y, en la escena bonaerense, gran cantidad de aficionades, de periodistas y de 
autores nombran a Iorio como patriarca, tanto para integrarlo al canon de bandas metálicas argentinas como para construir un contra-canon (Scaricaciottoli, 2017; Pisano, 2017). Ambas operaciones refuerzan, de igual modo, la idea de patriarcado.

\section{Las mujeres en la escena metálica bonaerense}

Debido a que esta investigación se centró en las tensiones que atraviesan les aficionades en la construcción identitaria metálica y la masculinidad heteronormativa solo ocupó uno sus ejes constitutivos, se decidió mantener el binarismo cisgenérico para indagar los espacios de agencia que ocupan en la escena las mujeres, los cuales no habían sido suficientemente profundizados en trabajos previos.

Lo anterior constituye una limitación, ya que durante la etnografía me enfoqué en aquellas características más evidentes y, en consecuencia, les aficionades con identidades genéricas disidentes quedaron relegades a espacios menos visibles. Esto constituye una debilidad en el abordaje de género dentro de la escena y una deuda para investigaciones futuras.

Debo explicitar, también, mi lugar de investigadora y de aficionada con agencia propia en dicho espacio. Esto tuvo ciertas ventajas, particularidades y limitaciones: primero, el fácil acceso al campo; segundo, la observación y la participación en la escena desde la perspectiva de una mujer, en condiciones desiguales con respecto a los varones; por último, la previa naturalización de la heteronormatividad que caracteriza al género musical y la necesidad de realizar un fuerte trabajo de reflexividad para el análisis social.

El interés por abordar los espacios de agencia femenina parte de una doble consideración, por un lado, varies autores afirmaron que las mujeres constituyen una minoría dentro de las escenas metálicas (Weinstein, 2000; Kahn-Harris, 2007); por otro, algunas estudiosas decidieron enfocar sus trabajos en la situación de algunas mujeres en particular (Dawes, 2012; Hill, 2013; Adamo, 2018). En efecto, en mi investigación observé esta minoría tanto cuantitativamente (mediante el rastreo de bandas de la escena bonaerense conformadas por mujeres) ${ }^{5}$ como cualitativamente. 
Para este último caso, pueden mencionarse diversas situaciones. Por ejemplo, mientras Walser ([1993] 2014) señala a la exscription (la idea utópica de un mundo con ausencia de mujeres) como una estrategia utilizada por las bandas metálicas de los ochenta, prácticamente no observé eventos especializados en metal que no contaran con la presencia de mujeres, las que generalmente nos encontramos integradas y ocupamos lugares tanto de músicas y aficionadas como de mediadoras (productoras, periodistas, fotógrafas y mánagers, investigadoras, entre otras).

No obstante, en la etnografía observé que algunos aficionados varones preferían las reuniones homosociales y se mostraban incómodos ante la presencia de mujeres. A pesar de ello, suelen exaltar su propia heterosexualidad y utilizan estos parámetros para evaluar la autenticidad de las aficionadas, quienes tienden a integrarse fácilmente a grupos de varones y se relacionan homosocialmente de manera escasa. Al igual que en la descripción de Leigh Krenske y Jim McKay (2000), el baño de mujeres (toilette) en los recitales suele ser el espacio que posibilita esto.

En efecto, en varias ocasiones del trabajo de campo estuve en reuniones donde era la única mujer presente. En ellas, observé a varones incómodos y a otros, con quienes tenía un trato de confianza, que actuaban de manera más relajada. Sin embargo, estos últimos marcaban las diferencias de género pidiéndome disculpas luego de eructar o de decir alguna grosería, advirtiendo que eso no debían hacerlo frente a una dama.

En estos grupos conformados totalmente por varones también viví otras formas de desigualdad de género que me relegaban a un lugar de desventaja: por ejemplo, las decisiones acerca de la realización de una actividad las tomaban ellos sin darme lugar a opinar. Al mismo tiempo, en las organizaciones grupales académicas y musicales -que integré temporalmente durante la etnografía- las mujeres solo ocupábamos lugares secundarios y permanecer en esta posición era el único modo de participar o de ser incluidas.

En este sentido, dentro de la escena, las mujeres no tenemos la misma autonomía que los varones y muchas concurrimos a los eventos especializados acompañadas por nuestras parejas, por grupos de amigues o por familiares. Los casos de mujeres que asisten solas son escasos y varias veces pude observar que los varones comentaban acerca de esto con extrañeza o, inclusive, intentaban acercarse con fines de conquista sexual. 
En el caso de las parejas heterosexuales, las mujeres también se encuentran en condiciones desiguales, ya que muchos varones modifican el trato para con ellas de acuerdo al grado de amistad y de respeto que tienen con su compañero varón. En el caso de los recitales, las prácticas corporales demuestran que las mujeres ocupan el lugar de trofeo, es decir, de una posesión que los varones ostentan ante sus pares viriles, mientras que ellos se muestran como protectores frente a la posible peligrosidad del pogo. Por ejemplo, estos aficionados se situan detrás de sus parejas mujeres, de forma muy próxima, abrazándolas por la cintura.

A pesar de que la sororidad no parece ser un rasgo característico entre las aficionadas al metal, algunas buscaban aumentar su protagonismo en la escena agrupándose con otras mujeres. Un ejemplo es el grupo de Facebook «Mujeres Del Metal Argentina!! [Unidas, Somos Más]», que se utilizaba para promocionar la actividad de bandas y emprendimientos realizados por mujeres metálicas. De todos modos, se trata de un grupo pequeño compuesto por 336 miembres.

\section{Las mujeres metálicas como tema de discusión intelectual y académica}

La necesidad de otorgar mayor visibilidad a la agencia de las mujeres de la escena cobró un peso importante entre les intelectuales dedicados al metal. Uno de los primeros trabajos es el artículo que Gito Minore (2016) escribió para resumir algunos puntos debatidos en la mesa redonda que integró la tercera Feria del Libro Heavy de la Ciudad Autónoma de Buenos Aires, en 2015, a la cual fui invitada a participar junto con Myriam Onchimiuk (periodista y webmaster) y Carine Alfie (guitarrista con una vasta trayectoria como solista que, en dicho momento, se integraba como invitada de la banda de Ricardo Iorio).

En dicho debate, las preguntas fueron moderadas por el propio Minore (es decir, un agente varón) y se enfocaron en nuestra experiencia como mujeres metálicas y en las dificultades que esto suponía. De esta manera, narramos experiencias personales que no siguieron una línea en particular pero que, en general, dieron cuenta de la ausencia de una toma de posición feminista dentro de nuestras propias percepciones acerca de la escena y el género musical.

En mi caso, solo mencioné algunas observaciones del incipiente trabajo de campo que estaba realizando para mi tesis doctoral, desprovistas de teoría y de análisis. Por ejemplo, comenté que algunas mujeres adecuaban ocasionalmente su vestimenta 
para acercarse a agentes de la escena (de forma similar a las groupies) y que algunos músicos varones abordaban a las aficionadas con fines sexuales. La postura de Alfie fue afirmar que, a su entender, la música no tiene género, mientras que Onchimiuk consideró que la principal característica del metal era que se conformaba como una familia.

Posteriormente, esto fue criticado por algunos sectores de la academia que, en lugar de problematizar dichas intervenciones en diálogo con el contexto, optaron por realizar reproducciones escritas parciales o distorsionadas, sin advertir la novedad que resultaba que tres participantes se expresaran públicamente en tanto mujeres en una escena en donde el componente masculino es predominante.

En el panel, la ausencia de juicios feministas tuvo un vínculo estrecho con lo que sucedía socialmente en otros planos. El movimiento \#NiUnaMenos, surgido en 2015, había puesto en agenda la situación de la mujer en la sociedad y permitía que los debates feministas de larga data comenzaran a tener lugar en espacios sociales más amplios y diversos como el de la música popular y, dentro de ella, el rock y el metal. Como sostienen Carolina Justo von Lurzer y Carolina Spataro (2016), la cultura popular «[...] no puede ser estudiada sino de modo histórico, situado, contextual y en movimiento» (p. 131).

En efecto, esta mesa redonda constituyó un punto inicial ya que, posteriormente, diverses intelectuales e investigadores comenzaron a realizar producciones escritas y audiovisuales orientadas a visibilizar la agencia de la mujer dentro de la escena (Lot Calabró \& Álvarez, 2015; Adamo \& Tellis, 2017; Adamo, 2018). No obstante, la mayoría de estos trabajos también adoptó una perspectiva cisgénero que no problematizó la masculinidad heteronormativa que predomina en el metal y con la cual las identidades de las mujeres (y las de les sujetes con géneros no normativos) entran en pugna de diversas formas.

A pesar de que gran parte de estas lecturas se realizaron desde una perspectiva feminista y buscaron denunciar los machismos y revalorizar a la mujer como agente social dentro de la escena -de manera similar a aquellos estudios que buscaban dar cuenta de la actividad de las músicas como un acto de conquista sobre espacios tradicionalmente dominados por varones (Green, 2001)-, los análisis estuvieron influidos por la perspectiva metálica heteronormativa, ya que no tuvieron en cuenta a las mujeres en tanto aficionadas. 
Algunos de esos trabajos expresaban la necesidad de modificar la perspectiva que se tenía acerca de las mujeres para "ser vistas como artistas, músicas, cantantes, gritadoras y no solo como chicas de póster/videoclip o groupies» (Adamo \& Tellis, 2017, p. 60). Tal como se indicó, el citado ensayo parece realizarse bajo la mirada crítica de la autenticidad metálica ya que solo rescata los roles femeninos protagónicos y niega la agencia de las modelos (mannequins) y las groupies. A su vez, no menciona ni problematiza qué sectores otorgan a las mujeres metálicas esos calificativos.

De acuerdo con Hill (2013), el concepto de groupie se constituyó como un mito que operó de manera negativa sobre los modos de interacción de las mujeres dentro de las escenas metálicas, ya que era utilizado por la prensa especializada en rock y metal de las décadas del setenta y ochenta para referirse a las aficionadas que mantenían relaciones sexuales con algunos músicos considerados estrellas de rock.

De esta manera, muchas mujeres debieron demostrar la veracidad de su gusto musical a través de diversas acciones (como convertirse en mediadoras o dejar de lucir visualmente femeninas) y de reprimir las posibilidades de sentir atracción sexual por sus ídolos musicales para poder ser integradas a la escena. A su vez, mediante este mito se les adjudicó heterosexualidad a los músicos varones de manera indiscutida. Por otra parte, estas normas morales se refuerzan con el valor positivo que se le da a la monogamia y el negativo que opera sobre la prostitución.

De todos modos, en la etnografía observé que varios músicos varones de la escena bonaerense (especialmente, los consagrados) utilizaban este mito para ubicarse en posiciones dominantes sobre las aficionadas. En ocasiones, algunos demostraron intenciones sexuales ${ }^{6}$ hacia aquellas mujeres que se acercaban a pedir un autógrafo o una fotografía o, como en mi caso, una entrevista -lo que motivó determinados recaudos metodológicos-.

En la escena metálica bonaerense, la autenticidad opera de manera opresiva sobre las mujeres, que deben demostrar no solo veracidad sino también excelencia como músicas, mediadoras y aficionadas, tanto frente a los agentes masculinos como ante sus pares femeninas. Pero, al mismo tiempo, el metal funciona como una herramienta de empoderamiento (Adamo, 2018) que, a diferencia de lo que sucede con los varones, les permite confrontar su lugar de marginalidad, tanto dentro de la propia escena como en la sociedad en general. 
Sin embargo, esto no se presenta de manera consciente y una gran cantidad de mujeres metálicas no adhieren al feminismo. Por el contrario, consideran que este movimiento se opone al metal, ya que creen que busca generar divisiones entre varones y mujeres. En ellas se observa el mito de la igualdad construido sobre el ideal de la hermandad metálica. Esto se hace evidente, especialmente, en aquellas aficionadas que son seguidoras de bandas metálicas que poseen canciones con letras misóginas y sexistas. En las entrevistas, algunas expresaron que no reconocían representaciones de violencia real hacia la mujer, sino solo formas de recreación artística de lo agresivo. En tanto, entre las que reconocían el machismo de estas producciones había dos posturas: las que se oponían totalmente y las que preferían obviarlo de manera consciente y decidían enfocarse en los elementos musicales de las bandas. Esto se produce, con mayor frecuencia, en aquellos subgéneros cuyos cantantes utilizan la técnica del growl, ${ }^{7}$ en la cual la voz cumple una función más musical que lingüística.

En este sentido, de las entrevistas se desprende que gran cantidad de aficionades construyen su gusto musical por medio de un vínculo emotivo con la música que, en muchos casos, no pueden explicar de manera racional. Es decir, las elecciones no responden a decisiones ideológicas. No obstante, es necesario aclarar que la música no funciona como alienante y estes agentes toman decisiones que completan su actividad de afición: seleccionan determinados subgéneros, bandas, conciertos, indumentaria y discos.

De esta manera, los análisis anteriormente mencionados parecen realizarse desde la misma perspectiva de autenticidad que juzga a las producciones, a les músiques y a les aficionades. Se busca confirmar la hipótesis del machismo presente en el metal sin problematizar la construcción de la cultura metálica en determinados contextos. A su vez, al criticar la ausencia de perspectivas feministas, el uso iconográfico de la mujer y la identidad de las groupies se reproduce el paradigma de autenticidad que espera del rock (y del metal) seriedad y compromiso político, y que rechaza el vínculo posible con la cultura de masas como sucede con algunas bandas metálicas consideradas mainstream y superficiales.

Por otra parte, estos trabajos académicos toman a las mujeres metálicas como objeto de estudio y, en lugar de problematizar la diversidad de feminidades, de experiencias de vida y de posturas ideológicas frente al feminismo y al propio metal, optan por juzgarla. Sin dejar de reconocer que constituyen un gran aporte 
para comenzar a reflexionar acerca de la cuestión de género dentro de la escena metálica argentina, deberíamos cuestionarnos los modos en que se construye conocimiento dentro de ella y qué lugar se adopta desde la investigación. Considero que cuando quien realiza la pesquisa tiene un vínculo muy estrecho con aquello que estudia es necesario realizar un fuerte trabajo de reflexividad que permita despejar el ojo observador de los prejuicios que son naturalizados en tanto agente previo de la escena estudiada.

\section{Feminidades metálicas: el look y el pogo}

Si se tiene en cuenta que a través del metal las aficionadas mujeres interactúan con elementos culturales codificados como hetero-masculinos, es posible decir que por medio de ellas se construyen formas de feminidad alternativas a la hegemónica y tradicional (Janotti Jr., 2013) y que, al mismo tiempo, tienden a romper con la propia perspectiva heteronormativa de la escena. Es decir, a pesar de que se valoran fuertemente la familia y los roles maternales y domésticos de las propias mujeres, ellas salen de estos espacios e ingresan a la escena de diversas maneras.

Las feminidades metálicas se pueden observar a través de dos prácticas corporales concretas: por un lado, las que tienen que ver con la vestimenta y el atuendo; por el otro, las relacionadas con la participación en el pogo. Para lo primero, distinguí dos situaciones distintas: mientras algunas mujeres deciden utilizar el look metálico de manera similar a los varones, sin destacar ningún rasgo de feminidad, otras buscan modos de exaltarlo.

Las primeras, a pesar de autopercibirse como mujeres, reniegan de la feminidad tradicional o la identifican con géneros musicales opuestos al metal (como el pop), y se encuentran más cómodas con la masculinidad que aquel les provee. Algunas deciden vestirse de forma unisex como una manera de mostrarse más auténticas. De esta forma, pude observar casos de parejas heterosexuales que lucían muy similares y solo se diferenciaban por medio del uso de barba en los varones y de maquillaje (especialmente, en los ojos y en la boca) en las mujeres.

En la otra vereda se encuentran las aficionadas que sí deciden exhibir feminidad y que buscan, para ello, modelos femeninos que no solo se diferencian de los tradicionales sino que se alinean con la intención de construir una identidad 
en apariencia amenazante. De esta manera, muchos atuendos se inspiran en figuras como brujas y vampiresas (Castillo Bernal, 2007) o toman elementos prostibularios y del BDSM. ${ }^{8}$

En este punto, es interesante mencionar que gran parte de la indumentaria metálica clásica proviene de este ámbito y de los circuitos gay de los ochenta (Clifford-Napoleone, 2015). Sin embargo, a lo largo del tiempo, les aficionades utilizaron el cuero, las tachas y las cadenas para construir una imagen masculina heteronormativa, alternativa a la hegemónica, que buscaba generar temor en aquelles a quienes se querían oponer.

El binarismo de género también se presenta en la propia industria de la indumentaria metálica. A diferencia de épocas anteriores, durante el período estudiado se incluyó la venta de ropa metálica dirigida especialmente a las mujeres. Esta se caracterizó por continuar los estereotipos de belleza hegemónica y de erotismo heteronormativo, debido a que se trataba de prendas ajustadas que no solían respetar la ley que exige la fabricación de talles grandes. ${ }^{9}$

Al mismo tiempo, estas ropas eran identificadas como metálicas no solo por el color negro sino también por tener estampas con iconografía de bandas metálicas, aunque estas solían ser de las más comerciales como Metallica y Guns 'N Roses. De esta manera, las mujeres continuaron siendo vinculadas con la idea de la música masiva y menos auténtica. Como consecuencia, gran cantidad de aficionadas adquirieron remeras unisex (utilizadas mayormente por varones) y les realizaron recortes de manera artesanal para otorgarles feminidad y, al mismo tiempo, lucir iconografía de bandas más auténticas. Otras, en tanto, crearon emprendimientos para confeccionar indumentaria con diseños personalizados.

En muchos casos, la feminidad también se construía mediante la utilización de peinados y de maquillajes, o del uso de accesorios como tacones y alhajas que, en la mayor parte de los casos, continuaban los parámetros hegemónicos de la moda femenina. Sin embargo, esto se combinaba con el despliegue de gestualidades codificadas como masculinas por no representar el recato y los buenos modales tradicionalmente esperados en la mujer: uso de vocabulario grosero, consumo de grandes cantidades de alcohol, contacto físico rudo y participación en el pogo. 
Este último, también llamado mosh-pit, se constituye como una performance que realiza el público durante los recitales, en la cual despliega violencia mediante ciertos códigos que garantizan su desarrollo pacífico. Allí, acciones como empujones, golpes de puño y patadas constituyen prácticas agresivas que no son utilizadas con el fin de enfrentarse físicamente sino para realizar una forma de baile.

La violencia desplegada en el pogo dialoga de diversas maneras con prácticas culturales que han sido codificadas como heteromasculinas. Por ejemplo, el uso corporal es similar al de algunas prácticas deportivas. De esta manera, en algunos aficionados varones pude observar una preparación previa (se despojan de los bienes que no quieren perder o romper, se sujetan el calzado, se colocan protectores bucales, etc.) así como ciertas actitudes recurrentes posteriores a la práctica: al finalizar, algunos se saludan y se felicitan.

Varios, además, ostentan los golpes recibidos o la rotura de algunas de sus prendas como una manera de demostrar orgullo por haberse desplegado con destreza dentro del mosh-pit y por haber podido aguantar. En este sentido, el pogo se vincula con la estética del aguante en el fútbol, en donde las cicatrices y las marcas corporales son testimonio de «una masculinidad legítima de los luchadores» (Alabarces, 2006, p. 4).

A pesar de que en el pogo se despliega violencia con códigos de nobleza y de inclusión, dicha camaradería se acerca a formas culturales heteromasculinas y tiende a ser homosocial (Krenske \& McKay, 2000; Gruzelier, 2013; Riches, Lashua \& Spraklen, 2014). Como consecuencia, cuando a dicha práctica ingresan mujeres se produce una ruptura con respecto a su propia dinámica, lo que evidencia que el lugar de los varones y las mujeres no es el mismo: ellos tienden a ocupar los sectores centrales, mientras que ellas se mantienen en los márgenes (Krenske \& McKay, 2000).

Durante las entrevistas, algunas aficionadas manifestaron el deseo de participar a la par de los varones, pero indicaron que temían sufrir mayores golpes si lo hacían en el centro. Por esa razón, relataron que solo propinaban empujones y patadas desde los costados o que acompañaban los movimientos haciendo headbanging. ${ }^{10}$ Algunas dijeron que no era lo mismo recibir el golpe de un varón que el de una mujer, por lo que anhelaban que otras aficionadas se animaran a integrarse a la práctica más asiduamente. 
Por su parte, las que prefieren evitar acercarse al pogo se mostraban incómodas si eran empujadas indirectamente, por lo que se mantenían alejadas de la práctica. Algunas eran utilizadas como percheros (Gruzelier, 2013) o como guardarropas, debido a que algunos varones les confiaban sus abrigos y sus pertenencias de valor. En efecto, muchas veces ocupé dicho rol y cuando me negaba a hacerlo, porque prefería participar del pogo, estos aficionados se mostraban sorprendidos y frustrados.

Para abordar más específicamente la práctica del pogo desde la perspectiva de una mujer, utilicé como herramienta metodológica la moshografía propuesta por Riches, Lashua y Spraklen (2014). A través de la inmersión crítica en este baile, noté que, en reiteradas ocasiones, los varones me esquivaban para no golpearme y, en otras, me pedían disculpas por haberme empujado o por haberme pisoteado involuntariamente. De cierta forma, algunos se mostraban protectores con las mujeres, a quienes perciben débiles.

\section{Algunas consideraciones}

En suma, es posible decir que, a pesar de que les agentes buscan expresarse en contra de la cultura hegemónica, la escena metálica bonaerense se encuentra culturalmente dominada por el sistema patriarcal. La heteronormatividad se presenta como un conjunto de normas éticas y estéticas que regulan social y culturalmente la escena por medio del paradigma de la autenticidad, el cual no solo se utiliza para juzgar la veracidad de les músiques y sus producciones, sino también de les propies aficionades y su agencia.

Como consecuencia, las prácticas sexuales y de género no normativas se presentan de manera poco visible. Contrariamente, es más evidente el valor otorgado a la familia tradicional y monogámica en tanto estructura que representa al ideal de la hermandad metálica y que permite la construcción de un canon de padres fundadores del género musical. Es así que la escena se muestra culturalmente conservadora.

Esto atenta, de manera particular, contra las mujeres a través del mito de la groupie y de la mirada negativa sobre quienes construyen sus identidades en diálogo con figuras femeninas consideradas poco decorosas. Lo mismo sucede con 
les aficionades que se vinculan con elementos identificados como femeninos y/o comerciales, ya sea subgéneros de metal considerados menos auténticos o prácticas sexuales y genéricas por fuera de la heterosexualidad.

De esta forma, las identidades de les agentes se construyan en disputa con la heteronormatividad. De modo que lo más visible es la identificación como varones y como mujeres metáliques. En ambos casos, la música funciona como una herramienta de empoderamiento que permite la construcción de identidades que se autoperciben como marginales y buscan lucir amenazantes y empoderades frente a une otre hegemónique.

No obstante, en las mujeres esto sucede de manera doble, ya que ocupan un lugar de marginalidad tanto en la sociedad como en la propia escena. Por medio del metal, un género musical dominado culturalmente por códigos masculinos heteronormativos, construyen feminidades alternativas que rompen tanto con el rol tradicional de la mujer (pasiva, doméstica, delicada y recatada) como con la moral patriarcal que se defiende en la escena.

Queda para estudios posteriores el análisis de las disidencias sexo-genéricas dentro de la escena y su interacción con la masculinidad heteronormativa predominante. Para ello, será necesario adoptar una perspectiva interdisciplinaria que permita indagar sobre las características y las particularidades históricas, antropológicas y comunicacionales, y que también tenga presente la transversalidad de la clase y la raza dentro de la construcción de diversas identidades metálicas.

\section{Referencias}

Adamo, N. y Tellis, P. N. (2017). Gritar o morir. En torno a la voz de las mujeres en el metal. En G. Minore (Comp.), Cultura metálica 4: ponencias, debates y exposiciones de la $4^{\circ}$ Feria del Libro Heavy de Buenos Aires (pp. 55-60). Ciudad Autónoma de Buenos Aires, Argentina: Clara Beter Ediciones. 
Adamo, N. (2018). Mujeres metálicas. Reflexiones en torno a la mujer en el heavy metal argentino. En E. Scaricaciottoli (Comp.), Parricidas: mapa rabioso del metal argentino contemporáneo (pp. 47-77). Ciudad Autónoma de Buenos Aires, Argentina: La Parte Maldita.

Alabarces, P. (1995). Entre gatos y violadores. El rock nacional en la cultura argentina. Ciudad Autónoma de Buenos Aires, Argentina: Colihue.

Alabarces, P. (2006). Fútbol, violencia y política en la Argentina: ética, estética y retórica del aguante. Esporte e Sociedade, (2), 1-14. Recuperado de https://www.ankulegi.org/wpcontent/uploads/2012/03/0102Alabarces.pdf

Arenillas Meléndez, S. (2016). Retromanía, artificio y transgresión del glam en la música popular española del siglo XXI. Cuadernos de música Iberoamericana, (29), 163-183. Recuperado de https://doi.org/10.5209/CMIB.56551

Bourdieu, P. (2000). La dominación masculina. Barcelona, España: Anagrama.

Butler, J. (2007) [1990]. El género en disputa. El feminismo y la subversión de la identidad. Barcelona, España: Paidós.

Castillo Bernal, S. (2007). El cuerpo humano como instrumento subcultural. De los inicios del heavy metal al simbolismo ritual del black metal. Fuentes humanísticas, 19(34), 43-57. Recuperado de http://fuenteshumanisticas.azc.uam.mx/index.php/rfh/article/view/306

Clifford-Napoleone, A. (2015). Querness in heavy metal music: metal bent [Lo queer en el heavy metal: metal torcido]. New York, United States: Routledge. 
Dawes, L. (2013). What Are You Doing Here? [¿Qué estás haciendo aquí?]. New York, United States: Bazillion Points.

Del Fresno, M. (2011). Netnografía. Investigación, análisis e intervención social online. Barcelona, España: UOC.

Flores, M. (1993). La música popular en el Gran Buenos Aires. Ciudad Autónoma de Buenos Aires, Argentina: Centro Editor de América Latina.

Fischerman, D. (2004). Efecto Beethoven. Complejidad y valor en la música de tradición popular. Ciudad Autónoma de Buenos Aires, Argentina: Paidós.

Frith, S. y McRobbie, A. (1978). Rock and Sexuality. Screen Education, (29), 3-19.

Green, L. (2001). Música, género y educación. Madrid, España: Morata.

Gruzelier, J. (2007). Moshpit Menace and Masculine Mayhem. En F. Jarman-Ivens (Ed.), Oh Boy! Masculinities and Popular Music (pp. 59-75). New York, United States: Routledge.

Hill, R. L. (2013). Representations and Experiences of Women Hard Rock and Metal Fans in the Imaginary Community (Tesis de Doctorado). Universidad de York, Reino Unido. Recuperado de https://pdfs.semanticscholar.org/70a9/26e329adcbeb180f37dff64e6fb2 7edb2633.pdf

Janotti Jr., J. (2004). Heavy Metal com Dendê. Rock pesado e mídia em tempos de globalização [Heavy metal con Dendê. Rock pesado y medios en tiempos de globalización]. Rio de Janeiro, Brasil: E-Papers editora. 
Janotti Jr., J. (2013). Rock with the devil: Notas sobre géneros e cenas musicais a partir da performatização do feminino no heavy metal. E S. Pereira de Sá y J. Janotti Jr. (Orgs.), Cenas musicais (pp. 73-89). Guararema, Brasil: Livraria Da Ana.

Justo von Lurzer, C. y Spataro, C. (2016). Cincuenta sombras de la cultura masiva. Desafíos para la crítica cultural feminista. Nueva Sociedad, (265), 117-131. Recuperado de https://www.nuso.org/media/articles/downloads/7._TC_Justo_265.pdf

Kahn-Harris, K. (2007). Extreme Metal. Music and Culture on the Edge [Metal extremo. Música y cultura en el borde]. Oxford, England: Berg.

Krenske, L. y McKay, J. (2000). «Hard and Heavy»: Gender and Power in a Heavy Metal Music Subculture. Gender, Place and Culture: A Journal of Femiist Geography, 7(3), 287-304.

Kimmel, M. S. (1997). Homofobia, temor, vergüenza y silencio en la identidad masculina. En T. Valdés y J. Olavarría (Eds.), Masculinidad/es. Poder y crisis (pp. 49-62). Santiago de Chile, Chile: Isis Internacional, FLACSO Chile.

Manzano, V. (2011). Tiempos de contestación: cultura del rock, masculinidad y política, 1966-1975. En S. Elizalde (Coord.), Jóvenes en cuestión. Configuraciones de género y sexualidad en la cultura (pp. 23-57). Ciudad Autónoma de Buenos Aires, Argentina: Biblos.

Martínez García, S. (1997). Músicas «populares» y musicología: aportaciones al estudio del heavy metal. Cuadernos de música Iberoamerica, (4), 241-257.

Martínez García, S. (2003). Decibelios y testosterona: una aproximación a las imágenes de género en el rock y el heavy metal. Dossiers feministes, 101-117. 
Minore, G. (2016). La figura de la mujer en el heavy metal argentino.

En G. Minore (Comp.), Cultura metálica 3. Ponencias, debates y exposiciones de la $3^{\circ}$ Feria del Libro Heavy de Buenos Aires (pp. 53-61). Ciudad Autónoma de Buenos Aires, Argentina: Clara Beter Ediciones.

Pisano, J. I. (2017). Heavy metal nacional: cómo matar al padre. Código y frontera, (s/d). Recuperado de http://www.codigoyfrontera.space/2017/10/06/heavy-metal-nacionalcomo-matar-al-padre/

Plesch, M. (2013). Demonizing and Redeeming the Gaucho: Social Conflict, Xenophobia and the Invention of Argentine National Music. Patterns of Prejudice, 47(4-5), 337-358. Recuperado de https://doi.org/10.1080/0031322X.2013.845425

Rappaport, J. (1984). Studies in Empowerment. Introduction to the Issue. Prevention in human services, 3(2-3), 1-7.

Riches, G., Lashua, B. y Spraklen, K. (2014). Female, Mosher, Transgressor: A «Moshography» of Transgressive Practices within the Leeds Extreme Metal Scene. IASPM Journal, 4(1), 87-100. Recuperado de https://iaspmjournal.net/index.php/IASPM_Journal/article/view/652

Scaricaciottoli, E. (2017). Vivir sin los padres, dilema del metal criollo. Andén, (87). Recuperado de http://andendigital.com.ar/2017/03/vivir-sin-los-padres-dilema-delmetal-criollo-anden-87/

Simonetto, P. (2016). La moral institucionalizada. Reflexiones sobre el Estado, las sexualidades y la violencia en la Argentina del siglo XX.e-l@tina, 14(55), 1-22. Recuperado de https://publicaciones.sociales.uba.ar/index.php/elatina/article/view/1774 
Vila, P. (1985). Rock Nacional. Crónicas de la resistencia juvenil.

En E. Jelin (Comp.), Los nuevos movimientos sociales (pp. 8-12).

Ciudad Autónoma de Buenos Aires, Argentina: Centro Editor de América Latina.

Wallach, J. y Levine, A. (2013). I Want You to Support Local Metal. A Theory of Metal Scene Formation. En T. Hjelm, K. Kahn-Harris y M. LeVine (Eds.), Heavy Metal. Controversies and countercultures (pp. 117-135). Sheffield, United Kingdom: Equinox.

Walser, R. (2014) [1993]. Running with the Devil: Power, Gender, and Madness in Heavy Metal Music [Corriendo con el demonio: poder, género y locura en el heavy metal]. Middletown, United States: Wesleyan University Press.

Weinstein, D. (2000) [1991]. Heavy metal. The Music and Its Culture [Heavy metal. La música y su cultura]. Boston, United States:

Da Capo Press.

Willis, P. E. (2014). Profane Culture [Cultura profana]. Reino Unido: Princeton University Press, 1978.

\section{Fuentes}

Lot Calabró, L. y Álvarez, P. (Directores y Productores) (2015). Sucio y desprolijo. El heavy metal en la Argentina [Documental]. Argentina

Malón (1995). Espíritu Combativo [CD]. Ciudad Autónoma de Buenos Aires, Argentina: EMI.

Malón (1996). Justicia o resistencia [CD]. Ciudad Autónoma de Buenos Aires, Argentina: EMI.

O’Connor (2004). «Deseo». En El tiempo es tan pequeño [CD]. Ciudad Autónoma de Buenos Aires, Argentina: PELO. 
Pappos’s Blues (1973). «Sucio y desprolijo». En Pappo’s Blues

Volumen 3 [Disco]. Ciudad Autónoma de Buenos Aires, Argentina:

Music Hall.

Rotas Cadenas (2013). Rotas cadenas [demo].

\section{Notas}

1 La tesis doctoral, titulada «La escena bonaerense de la música metal: estudio en torno

a Hermética como centro de sentidos y disputas», fue realizada para el doctorado en Comunicación de la Facultad de Periodismo y Comunicación Social de la Universidad Nacional de La Plata (UNLP) y financiada con una beca interna doctoral otorgada por el Consejo Nacional de Investigaciones Científicas y Técnicas (CONICET). Contó con la dirección de la Dra. Olga Echeverría y la codirección del Prof. Sergio Pujol.

2 Dado que este artículo pretende ser un aporte para la erradicación de diversas formas de violencia y de discriminación, resulta coherente buscar modos de comunicación que sean inclusivos. En esta línea, decidí hacer uso del lenguaje incluyente y no sexista en su versión con la letra «e», ya que el mismo permite nombrar de manera respetuosa a las personas que no se identifican con, y que cuestionan, el binarismo de género masculino y femenino. Asimismo, la adhesión a esta forma de lenguaje tiene como fin el respeto por la diversidad y por la lucha política por la igualdad de derechos, a través del cuestionamiento de los estereotipos que provienen del paradigma androcéntrico y cis-hetero-patriarcal.

3 En este, y en todos los casos mencionados a lo largo del trabajo, me refiero a varones cisgénero.

4 Feria que se realiza desde 2013 en la Ciudad Autónoma de Buenos Aires, y en otras ciudades argentinas, con el objetivo de difundir el material escrito acerca del metal, así como de exponer y de vender objetos culturales especializados en dicho género musical.

5 Rastreo realizado en el sitio Enciclopedia Metallum. The Metal Archives.

6 A partir de las entrevistas, pude saber que algunos de estos acercamientos con fines sexuales posteriormente se concretaron de manera consentida. No obstante, los escraches realizados por la grupa UTFU permiten considerar la posibilidad de la existencia de abusos sexuales no denunciados y/o silenciados, tal como sucedió en otras escenas musicales, especialmente del rock. En efecto, mediante la autoetnografía constaté que algunos varones aprovechan las ocasiones multitudinarias para tocar a las mujeres sin su consentimiento.

7 Esta técnica consiste en cantar con un sonido rasposo. En algunos casos, este sonido es similar a un ronquido, lo que dificulta la vocalización clara de las palabras. 
8 Sigla que combina las letras iniciales de las palabras Bondage, Disciplina, Dominación, Sumisión, Sadismo y Masoquismo.

9 Se trata de la Ley 12.665 de la provincia de Buenos Aires, conocida como «Ley de talles» (promulgada en 2001 y reglamentada en 2005).

10 Práctica que consiste en sacudir violentamente la cabeza al ritmo de la música. 